\title{
Tuberculosis
}

\author{
Evan Freeman ${ }^{\mathrm{A}}$ and Stephen Conaty ${ }^{\mathrm{B}}$ \\ ${ }^{\mathrm{A}}$ NSW Public Health Officer Training Program, NSW Ministry \\ of Health \\ ${ }^{\mathrm{B}}$ Public Health Unit, South Western Sydney and Sydney Local \\ Health Districts
}

Tuberculosis infection occurs in all countries of the world, and is caused by organisms of the Mycobacterium tuberculosis complex. ${ }^{1}$ In recent decades the development of multidrug-resistant tuberculosis and the presence of human immunodeficiency virus (HIV) have combined to increase the global threat to public health posed by tuberculosis. In 2010 there were 8.8 million new cases of tuberculosis worldwide, with more than 50\% from South East Asia and the Western Pacific Region. ${ }^{2}$ In 2009, the estimated global incidence of tuberculosis was 128 cases per 100000 population; ${ }^{2}$ in Australia the notification rate was 6.2 per $100000,{ }^{3}$ and in NSW there were 508 notified cases with an incident rate of 7.2 per 100000 (data not yet published).

Transmission occurs from individuals with active pulmonary tuberculosis by the airborne route. ${ }^{2}$ Household contacts and other close contacts are exposed when tuberculosis bacilli are expelled into the air by coughing, sneezing or talking. Most people develop an inactive form of disease (latent tuberculosis), which is asymptomatic and not infectious. Those who have latent tuberculosis have a $10 \%$ lifetime risk of progressing to active infection, with half $(5 \%)$ occurring within 1-2 years after initial infection. $^{1,2}$ The likelihood of developing active disease is increased in the presence of impaired immunity from HIV, malnutrition, drug and alcohol use, other immune suppressive conditions, or treatments for cancer, diabetes and kidney disease.

The minimum period of treatment for tuberculosis is 6 months, and will typically use a starting regimen of four drugs (isoniazid, rifampicin, pyrazidamine and ethambutol). Compliance with treatment in most patients is facilitated by directly observed therapy short course (DOTS), which is recommended by the World Health Organization. Multidrug-resistant tuberculosis (MDR-TB), is resistant to at least isoniazid and rifampicin; extensively resistant tuberculosis is additionally resistant to other second-line drugs, complicating the medical and public health management of people with the infection. ${ }^{4}$ In NSW all cases of multidrug-resistant tuberculosis are referred to the NSW Health MDR TB Expert Panel.

The early detection and treatment of people with tuberculosis and assessment of close contacts at risk of infection are important for reducing further transmission. Cases and their contacts that have been exposed to active tuberculosis receive education, testing and support through the network of 29 Chest Clinics in NSW. It is through these clinics that DOTS is managed.

\section{Public Health Orders and tuberculosis}

A Public Health Order is a rarely used legal instrument in NSW which is designed to protect the public from an individual whose medical condition and behaviour may place others at risk. It can only be made after other strategies to establish and maintain adherence to care or treatment are exhausted. Under the NSW Public Health Act 1991 a person must have a specified condition (avian influenza, severe acute respiratory syndrome (SARS), tuberculosis, typhoid or AIDS/HIV) and he or she must be behaving in a way that is endangering or likely to endanger the health of the public. The Public Health Order is made by the Chief Health Officer or medical practitioner authorised by the Director General, and is valid for a period up to 28 days. The Order may require the person to whom it applies to undergo one or more of the following:

- refrain from a specified conduct

- undergo specified treatment

- undergo counselling by a specified person or by one or more persons belonging to a specified class of persons

- submit to the supervision of a specified person or one or more persons belonging to a specified class of persons

- be detained while undergoing treatment.

In NSW in the period 2000-2010 there have been 10 such orders for people with tuberculosis infection.

\section{References}

1. Heymann DL, ed. Control of Communicable Diseases Manual. 19th edition. Washington: American Public Health Association; 2008.

2. World Health Organization. WHO Report 2011. Global tuberculosis control. WHO/HTM/TB/2011.16. Geneva: World Health Organization; 2011. Available at: http://www.who.int/tb/ publications/global_report/2011/gtbr11_main.pdf (Cited 18 January 2012).

3. NNDSS Annual Report Writing Group. Australia's notifiable disease status, 2009: annual report of the National Notifiable Diseases Surveillance System. Commun Dis Intell 2011; 35(2): 61-131. Available at: http://www.health.gov.au/internet/main/ publishing.nsf/content/cda-cdi3502-pdf-cnt.htm/\$FILE/ cdi3502a.pdf (Cited 18 January 2012).

4. Centres for Disease Control and Prevention. Emergence of Mycobacterium tuberculosis with extensive resistance to secondline drugs worldwide, 2000-2004. MMWR Morb Mortal Wkly Rep 2006; 55: 301-5. Available at: http:/www.cdc.gov/mmwr/ preview/mmwrhtml/mm5511a2.htm (Cited 16 September 2011). 